BRD 50228

\title{
Presence of a Novel Epithelial Antigen on Rat Cerebellar Cell Lines as Detected by a Monoclonal Antibody
}

\author{
G. J. GIOTTA ${ }^{1}$, J. G. HEITZMANN'1 , M. DuBOIS² and P. D. BOWMAN 2 \\ ${ }^{1}$ Salk Institute, Developmental Biology Laboratory, San Diego, CA 92138 and 2 Department of Pediatrics, \\ University of Michigan, Ann Arbor, MI (U.S.A.)
}

(Accepted January 21st, 1985)

Key words: cerebellar — rat cell line - monoclonal antibody - Rous sarcoma virus - epithelial antigen

\begin{abstract}
We have derived a monoclonal antibody, MCAb 51, following immunization of BALB/c mice with a Rous sarcoma virus-transformed rat cerebellar cell line. When assayed by immunofluorescence on primary rat cerebellar cultures MCAb 51 recognizes only islands of cells with an epitheloid morphology. Double-label immunofluorescence experiments with MCAb 51 and antisera to tetanus toxin, glial fibrillary acidic protein, galactocerebroside and fibronectin reveal that these cells do not appear to be neurons, astrocytes, oligodendrocytes, or fibroblasts, respectively. In contrast, cells from kidney, liver, tongue and choroid plexus epithelium are positive for the antigen. Of 12 Rous sarcoma virus-transformed cell lines, in contrast to 2 out of 9 chemically transformed lines, 11 exhibit the MCAb 51 antigen. These findings demonstrate that MCAb 51 recognizes an epithelial cell surface marker. Possible explanations for the difference in the expression of the antigen on Rous sarcoma virus and chemically transformed neural lines are discussed.
\end{abstract}

\section{INTRODUCTION}

Clonal cell lines that exhibit different degrees of differentiated properties are potentially powerful tools with which to study the lineages of neural cells, and those factors responsible for maintaining the lineages. Ideally, it should be possible to determine the position that a cell type occupies in a particular lineage by assessing the level of expression of specific neural properties. To this end we have established a library of Rous sarcoma virus (RSV)-transformed rat cerebellar cell lines and have previously reported the results of studies concerning the characterization of two of them ${ }^{5-7}$. These lines were shown to be either neuronal or glial based on their capacity to exhibit veratridine stimulated $\mathrm{Na}^{+}$uptake, or glial fibrillary acidic protein (GFAP) respectively ${ }^{6}$. Prior to our work cell lines established with RSV were thought to be exclusively glial. In a subsequent communication we showed the presence of an antigen on both cell lines which in normal rat cerebellar tissue is shared by granule cell neurons and astrocytes as revealed by a monoclonal antibody5.
In this report we extend our prior observations by describing the cell type specificity of another monoclonal antibody, MCAb 51, for a large number of neural cell lines. MCAb 51 was derived using a RSV transformed cerebellar cell line as the immunogen. MCAb 51 is highly specific when assayed on primary cerebellar cultures and is restricted to islands of cells with an epitheloid morphology. In contrast, when screened against either neuronal or glial RSV-transformed cerebellar cell lines $\mathrm{MCAb} 51$ recognizes both cell types.

These findings suggest that the cerebellar cell lines, regardless of their neural phenotype, share a common neuroepithelial origin. The significance of this work with regard to the lineage of the RSVtransformed cerebellar cell lines as well as its relevance to neural development is discussed.

\section{MATERIALS AND METHODS}

\section{Reagents}

Fluorescein or rhodamine labeled goat anti-mouse or goat anti-rabbit immunoglobulin ( $\mathrm{Ig}$ ) was ob-

Correspondence: G. J. Giotta, Salk Institute, Developmental Biology Laboratory, P.O. Box 85800, San Diego, CA 92138, U.S.A 
tained from Cappel Laboratories. Antisera to human fibronectin was made in rabbits and obtained from Collaborative Research. Tetanus toxin and antisera to the toxin were the kind gifts of Dr. R. O. Thompson of Wellcome Research Laboratories. Antisera to galactocerebroside was made in rabbits as described previously ${ }^{4}$. Antisera to glial fibrillary acidic protein ${ }^{1}$ was made in rabbits and was the gift of Dr. Amico Bignami of Harvard University. Thy-1 antisera were made in rabbits as described previously ${ }^{14}$. The MCAb 04 was the kind gift of Dr. M. Schachner of the University of Heidelberg, F.R.G. DNAase I was obtained from Calbiochem.

\section{Cell lines}

$R S V$-transformed neural lines. All the RSV-transformed cerebellar cell lines were derived from cerebellar primary cultures started from BDIX rats that were between 3 days prenatal and 12 days postnatal. The details have been reported previously ${ }^{2,5}$. The viruses used were either a $t s s r c$ mutant, Schmidt-Ruppin Subgroup D LA90, or its wild-type parent. The ts-RSV-transformed lines exhibit a transformed phenotype at the permissive temperature (PT, $33-34{ }^{\circ} \mathrm{C}$ ) and a normal phenotype at the non-permissive temperature (NPT, $38-39^{\circ} \mathrm{C}$ ). The wildtype-transformed lines exhibit a transformed phenotype at both temperatures. These lines have been tentatively classified as either neuronal or glial depending on whether they do or do not exhibit veratridine-stimulated $\mathrm{Na}^{+}$uptake.

$N$-ethyl-N-nitrosourea transformed brain lines. $\mathrm{N}$ ethyl-N-nitrosourea (ENU)-transformed rat cell lines were obtained from Dr. David Schubert at the Salk Institute. Their properties have been described in detail ${ }^{23}$.

Other cell lines. The rat kidney cell line NRK LA29 , transformed with a Prague strain of RSV subgroup $\mathrm{A}^{2}$, was the gift of Dr. Peter Vogt, at the University of Southern California.

\section{Production of MACb 51 hybridoma}

Approximately $10^{7} \mathrm{SC} 9$ cells grown at $38^{\circ} \mathrm{C}$ were injected subcutaneously into $\mathrm{BALB} / \mathrm{c}$ mice in a mixture of phosphate buffered saline (PBS) and complete Freunds adjuvant. The mice were given a tail vein injection of $10^{5}$ cells in PBS 3 weeks later. The spleens were removed 4 days later and the spleen cells fused to the mouse myeloma cell line SP2/0Ag1424. Standard fusion techniques were followed using polyethylene glycol 1500 as the fusing agent. The cells were incubated overnight in Dulbecco's modification of Eagle's medium (DMEM) supplemented with $20 \%$ fetal calf serum (FCS). The next day the medium was replaced with medium containing hypoxanthine, aminopterin and thymidine. Clones were apparent in two weeks. The supernatants from the clones were tested for antibody secretion by immunofluorescence on SC9.

Hybridoma ascites fluid was made by injecting approximately $5 \times 10^{6}$ cells into $\mathrm{BALB} / \mathrm{c}$ mice which were pretreated with $0.5 \mathrm{ml}$ of pristane given i.p.

\section{Primary culture techniques}

Cerebellar cultures. Primary cerebellar cultures were started from 3-5-day-old rats essentially by the method of Schier et al.22. Briefly this consisted of removing the meninges, dissecting out the cerebellum, and mincing it into fine pieces with scissors in cold HEPES medium. The tissue was then digested with $0.25 \%$ trypsin for $30 \mathrm{~min}$ at $37^{\circ} \mathrm{C}$. DNAase $(40$ $\mu \mathrm{g} / \mathrm{ml}$ ) was routinely added to prevent cell clumping which arises as a consequence of DNA being released from fragmented nuclei in the digestion mixture. Trypsinization was stopped by the addition of an equal volume of DMEM plus $20 \%$ FCS. The cells were washed $3 \times$ with DMEM plus $20 \%$ FCS and grown on coverslips containing the same media but with an elevated level, $20 \mathrm{mM}$, of $\mathrm{K}^{+}$. Thy-1 staining was done on cells kept in culture for 10 days.

Mammary and liver epithelial cultures. Mammary epithelial cultures were prepared according to Topper et al. ${ }^{28}$. Such cultures routinely contained cells with large vacuoles. Presumably the vacuoles contain milk proteins and fat. Rat liver primary cultures were prepared according to Leffert et al. ${ }^{13}$. Both rat liver and mammary epithelial cultures were stained with MCAb $5148 \mathrm{~h}$ after preparation.

\section{Fluorescence staining techniques}

Primary cultures. Primary cultures were stained with MCAb 51 antibody after being kept in culture for 5-7 days. This consisted of rinsing with HEPES or DMEM and incubating the cultures with antibody for $30 \mathrm{~min}$ at $37^{\circ} \mathrm{C}$ in a $\mathrm{CO}_{2}$ incubator. Cultures were then washed $3 \times$, allowing $5 \mathrm{~min}$ between washings 
and incubated with the second fluorescent labeled antibody for $30 \mathrm{~min}$ at $37^{\circ} \mathrm{C}$. The cultures were then washed and fixed for $5 \mathrm{~min}$ in a mixture of cold $95 \%$ ethanol, 5\% acetic acid. Lastly, the cultures were rinsed and mounted in PBS containing $10 \%$ glycerol. The procedure for double-label experiments with MCAb 51 and antisera to tetanus toxin, galactocerebroside and fibronectin was similar except that there were two additional antibody reaction and washing steps. Double-label experiments with MCAb 51 and antisera to GFAP were done by first having the cells react with $\mathrm{MCAb} 51$, then fixing them with cold $95 \%$ ethanol, $5 \%$ acetic acid followed by incubation with antisera to GFAP. MCAb 51 ascites fluid was used at 1/50-1/500 dilution.

Tetanus toxin was used at a concentration of 10 $\mu \mathrm{g} / \mathrm{ml}$. Rabbit antitoxin was used at a 1/20-1/50 dilution. Antisera to galactocerebroside and fibronectin were also used at $1 / 20-1 / 50$ dilution.

Factor VIII staining was performed as described by Jaffe et al. ${ }^{16}$.
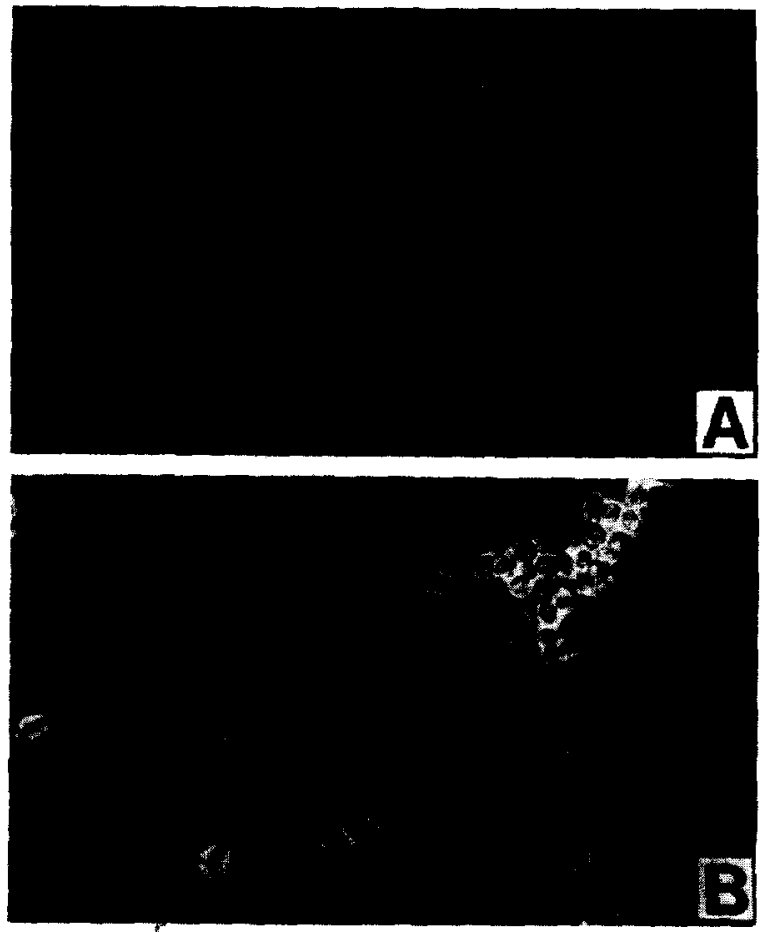

Fig. 1. Immuhofluorescence staining with MCAb 51 in a primary cerebellar culture. Labeling is restricted to cells which grow in colonies and the fluorescence intensity appears greatest at the edges of the colony. Note that putative granule neurons in the upper right corner of the picture are not labeled. A: fluorescence; B: phase contrast. $491 \times$.

\section{Cell lines}

All cell lines were grown in $60-\mathrm{mm}$ tissue culture dishes in DMEM plus 10\% FCS. About $2.5 \times 10^{5}$ cells were seeded per dish and kept at either the PT $\left(33-34{ }^{\circ} \mathrm{C}\right)$ or the NPT $\left(38-39{ }^{\circ} \mathrm{C}\right)$ for 4 days. Subsequently the cultures were washed with PBS containing $2 \% \mathrm{FCS}$ and viable cells incubated with the hybridoma antibody. Cells were incubated for 30 min at $37^{\circ} \mathrm{C}$, washed $3 \times$ and then incubated with rhodamine-labeled goat anti-mouse for another 30 min. The last incubation was followed with 3 more washings, then fixation of the cells with a mixture of cold $95 \%$ ethanol, $5 \%$ acetic acid. Initial experiments revealed that post-fixation did not alter the fluorescence profile of the cells.

\section{Frozen tissue sections}

Tissue from adult BD-IX rats was removed and frozen on dry ice. Sagittal sections $10 \mu \mathrm{m}$ thick were cut on a cryostat at $-20^{\circ} \mathrm{C}$. Sections were incubated with first and second antibodies and subsequently fixed as described for the cell lines.

\section{RESULTS}

The specificity of MCAb 51 was assayed on primary cultures. Fig. 1 shows that the cell type recognized by the antibody is invariably flat and often found in small colonies. It is worth noting that the fluorescence staining is not uniform across the colony, rather cells at the edges exhibit considerably more intense fluorescence than do cells in the interior. Initially we thought this might be due to a piling up or multilayering of cells at the edges. However, observations on numerous colonies suggest that this is probably not the case since colonies without obvious multilayering also exhibit more intense fluorescence at the edges.

The number of colonies apparent in a $60-\mathrm{mm}$ tissue culture dish varies from preparation to preparation of primary cultures. However, starting from an initial inoculum of $2 \times 10^{6}$ cerebellar cells there are approx. 1-10 colonies per dish after 7 days in vitro. The number of cells within the colonies also varies and ranges from about a dozen to several hundred cells. Colonies are not apparent until $48 \mathrm{~h}$ after the culture is started and persist for at least 10 days after which time they become overgrown by other cell 
types. Colonies do not show vigorous growth, but the appearance of mitotically active cells either in, or more often on the edges of the colonies, as well as the observation that the colonies do increase in size with time, suggest that the cells grow in vitro.

\section{Binding of MCAb 51 to neural cell lines}

Table I shows that of 12 RSV-transformed cerebellar cell lines screened by immunofluorescence 11 bind MCAb 51. The expression of the antigen in those lines transformed with ts-RSV is apparent at both the PT and NPT. Fig. 2 shows the staining profile associated with one positive RSV cell line and R2 the only RSV which does not bind MCAb 51 . In contrast to the results obtained with the RSV transformed cell lines, most cell lines transformed with the chemical carcinogen ENU do not exhibit the antigen.

\section{TABLE I}

MCAb 51-binding to the cell lines examined

$\mathrm{N}$ means neuronal and $\mathrm{G}$ means glial cell line. $\mathrm{N}, \mathrm{G}$ refers to cell lines which exhibit properties of both neurons and glia. + MCAb 51 -binding line, -, non-MCAb 51-binding line.

$\begin{array}{lr}\text { RVS-transformed lines } & \\ \mathrm{SC} 9(\mathrm{~N}) & + \\ \mathrm{R} 2(\mathrm{~N}) & - \\ 19(\mathrm{~N}) & + \\ \mathrm{WC5}(\mathrm{N}, \mathrm{G}) & + \\ 12(\mathrm{G}) & + \\ 10 \mathrm{D}(\mathrm{G}) & + \\ \mathrm{COA}-2(\mathrm{G}) & + \\ 17 \mathrm{D}(\mathrm{G}) & + \\ \mathrm{HKCl}(\mathrm{G}) & + \\ \mathrm{WtCl}_{4}(\mathrm{G})^{*} & + \\ \mathrm{WtCl}_{2}(\mathrm{G})^{*} & + \\ \mathrm{BC6}(\mathrm{G}) & +\end{array}$

ENU-transformed lines

$\mathrm{B} 12(\mathrm{G})$

$\mathrm{B} 15(\mathrm{G})$

$\mathrm{B} 19(\mathrm{G})$

$\mathrm{B} 35(\mathrm{~N})$

$\mathrm{B} 49(\mathrm{~N}, \mathrm{G})$

$\mathrm{B} 50(\mathrm{~N})$

$\mathrm{B} 92(\mathrm{G})$

$\mathrm{B} 103(\mathrm{~N})$

$\mathrm{B} 104(\mathrm{~N})$

\section{Other cell lines}

$\mathrm{C} 6(\mathrm{G})$

$\mathrm{PC} 12^{* *}(\mathrm{~N})$

* $\mathrm{WtCl}$ and $\mathrm{WtCl}_{2}$ were derived with a wild-type Rous sarcoma transforming virus.

** The PC12 cell line was derived from a tumor of the adrenal medulla and had properties of a sympathetic neuron.
Only 2 out of 9 lines are positive (Table I). Table I also shows that the cell lines $\mathrm{C} 6$ and $\mathrm{PC} 12$ do or do not display the antigen, respectively. It is worth noting that both neuronal and non-neuronal lines express the antigen regardless of whether the cell lines were derived by transformation using RSV or ENU.

\section{Cell type specificity of $M C A B 51$ in primary cerebellar cultures}

The epitheloid-looking colonies were screened by double-label immunofuorescence to determine if they exhibit neuronal or glial properties. Fig. 3 shows the results of using MCAb 51 in combination with either rabbit antisera against tetanus toxin, GFAP or galactocerebroside. These antisera recognize neurons ${ }^{15}$, astrocytes ${ }^{1}$ and oligodendrocytes ${ }^{20}$ respectively. It is apparent from Fig. 3 that the colonies do not exhibit any of these markers.

In addition to the oligodendrocyte marker galactocerebroside the epitheloid colonies were screened for the presence of another oligodendrocyte marker, the 04 antigen. While galactocerebroside is restricted to mature oligodendrocytes, the specificity of 04 encompasses immature as well as mature oligodendrocytes $^{26}$. Because 04 is a mouse antibody we did not attempt to do double-label experiments, rather we relied on the characteristic colony morphology of MCAb 51-positive cells to determine if 04 recognizes these cell types. The results revealed no staining of the colonies with 04 (data not shown). These findings suggest that the antigen is not carried by either mature or immature oligodendrocytes.

Further, Figs. 4 and 5 show that MCAb 51-positive colonies are fibronectin- and Thy-1-negative. Thy-1 is present on neurons, astrocytes and fibroblasts in the brain ${ }^{4.18}$ while fibronectin has been shown to be absent on these cell types but present on meningeal, choroid plexus, fibroblast and endothelial cells ${ }^{19.21}$.

In order to test directly whether the colonies are endothelial cells, two additional experiments were done: first, primary cerebellar cultures were stained with antisera against Factor VIII, and second, rat brain and rat capillary cultures enriched for endothelial cells were assayed by immunofluorescence for MCAb 51. Factor VIII has been shown to be a marker for endothelial cells ${ }^{16}$. We observed that MCAb 51-positive colonies are negative for Factor VIII. Factor VIII positive cells are, however, present in 

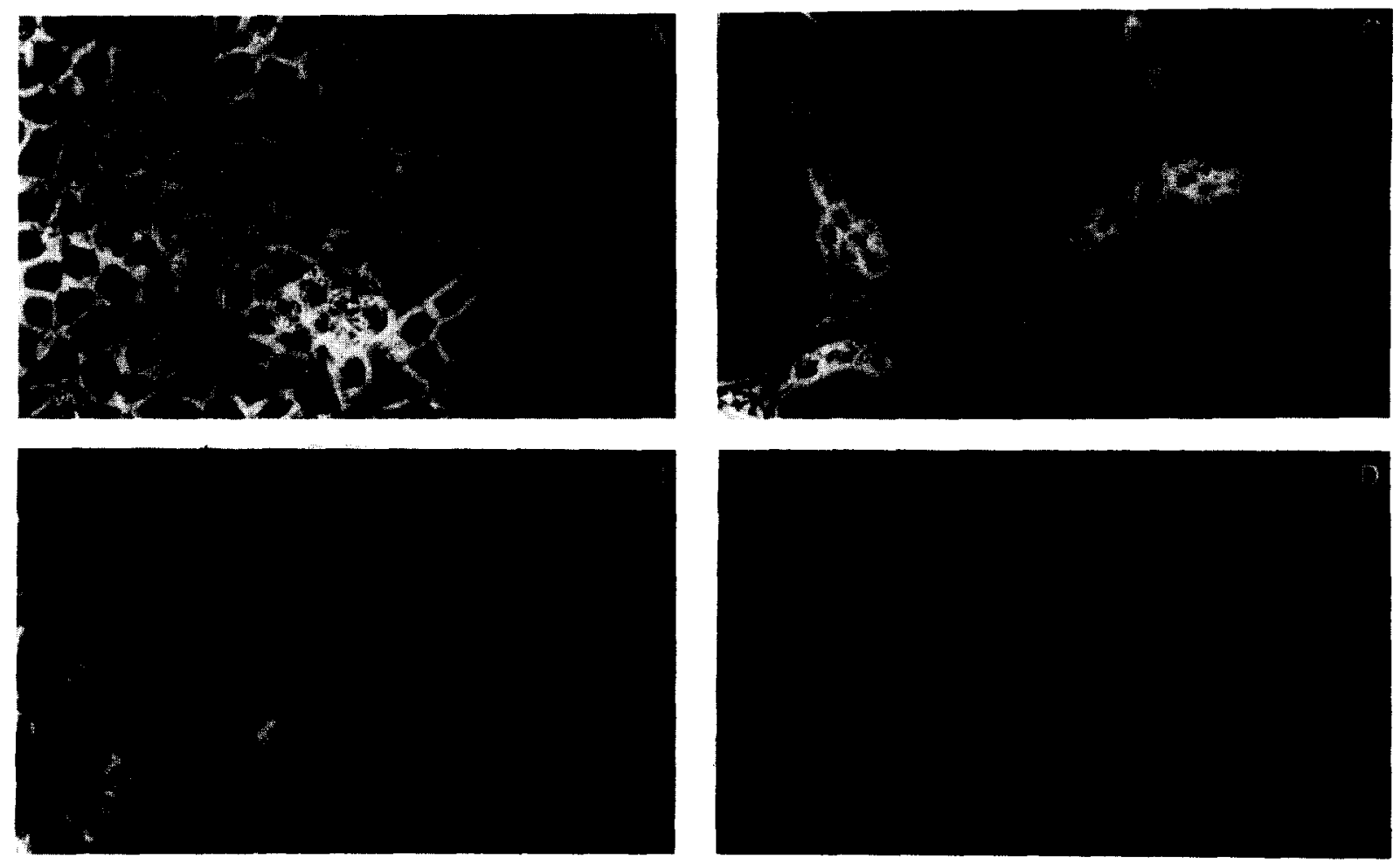

Fig. 2. Binding of MCAb 51 to two RSV-transformed cell lines, WC5 and R2. A shows phase and B fluorescence pictures of WC5, while $C$ shows phase and $D$ fluorescence pictures of $R 2$. Note that MCAb 51 does not recognize R2. 388X.
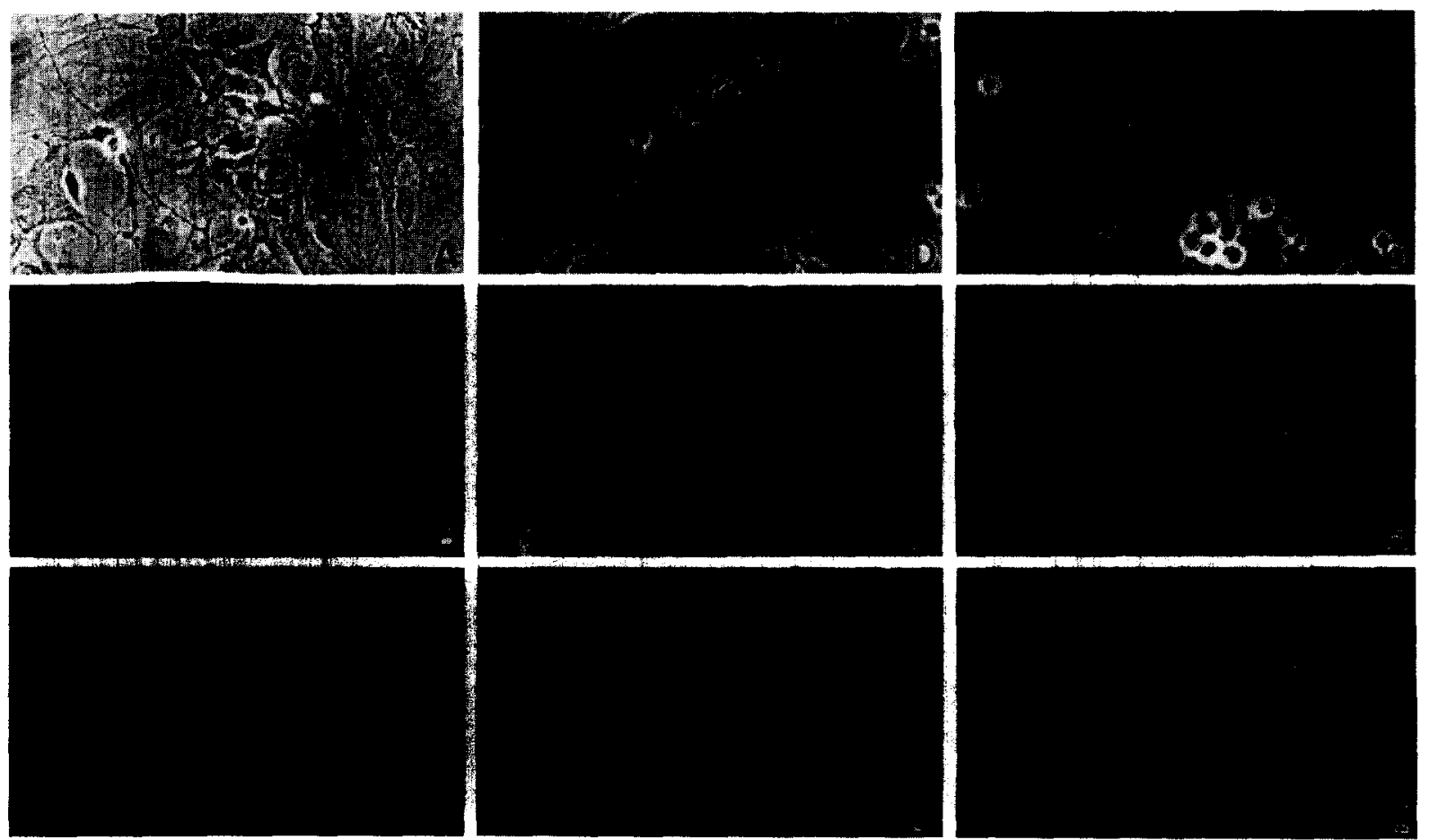

Fig. 3. Double-label immunofluorescence experiments with MCAb 51 and rabbit antisera to tetanus toxin, GFAP and galactocerebroside. $A, D$, and $G$ are phase pictures; $B, E$ and $H$ are fluorescence pictures of cells stained with rabbit antisera to tetanus toxin, GFAP and galactocerebroside, respectively. C, F and I are fluorescence pictures of cells stained with MCAb 51. Pictures A-C, and D-F, and G-I are of identical fields. Note that neither neurons (B, C), nor astrocytes, shown surrounding a colony of MCAb 51 positive cells (E, F), nor oligodendrocytes (H, I) bind MCAb 51. 303×. 


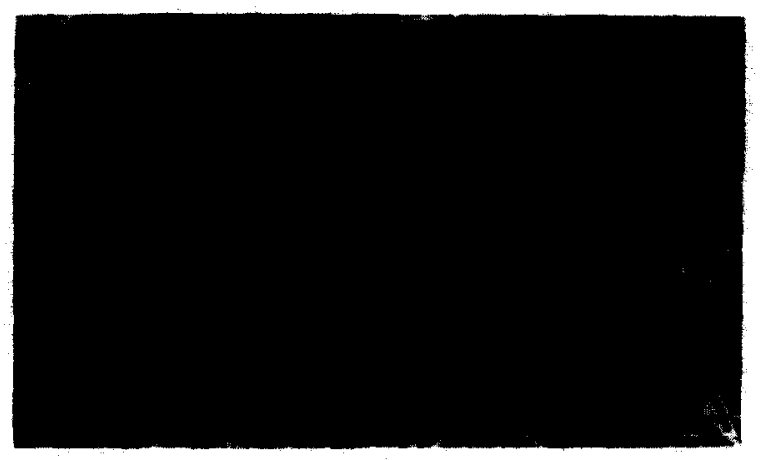

thelial cell types were screened to determine if the antibody is epithelial cell-type specific. Fig. 7 shows that MCAb 51 binds to both mammary and liver epithelial cells when assayed on primary cultures. Fig. 8 shows MCAb 51 staining of kidney and tongue epithelium in frozen sections. Staining in kidney sections is specific and is not due to antibody trapping since
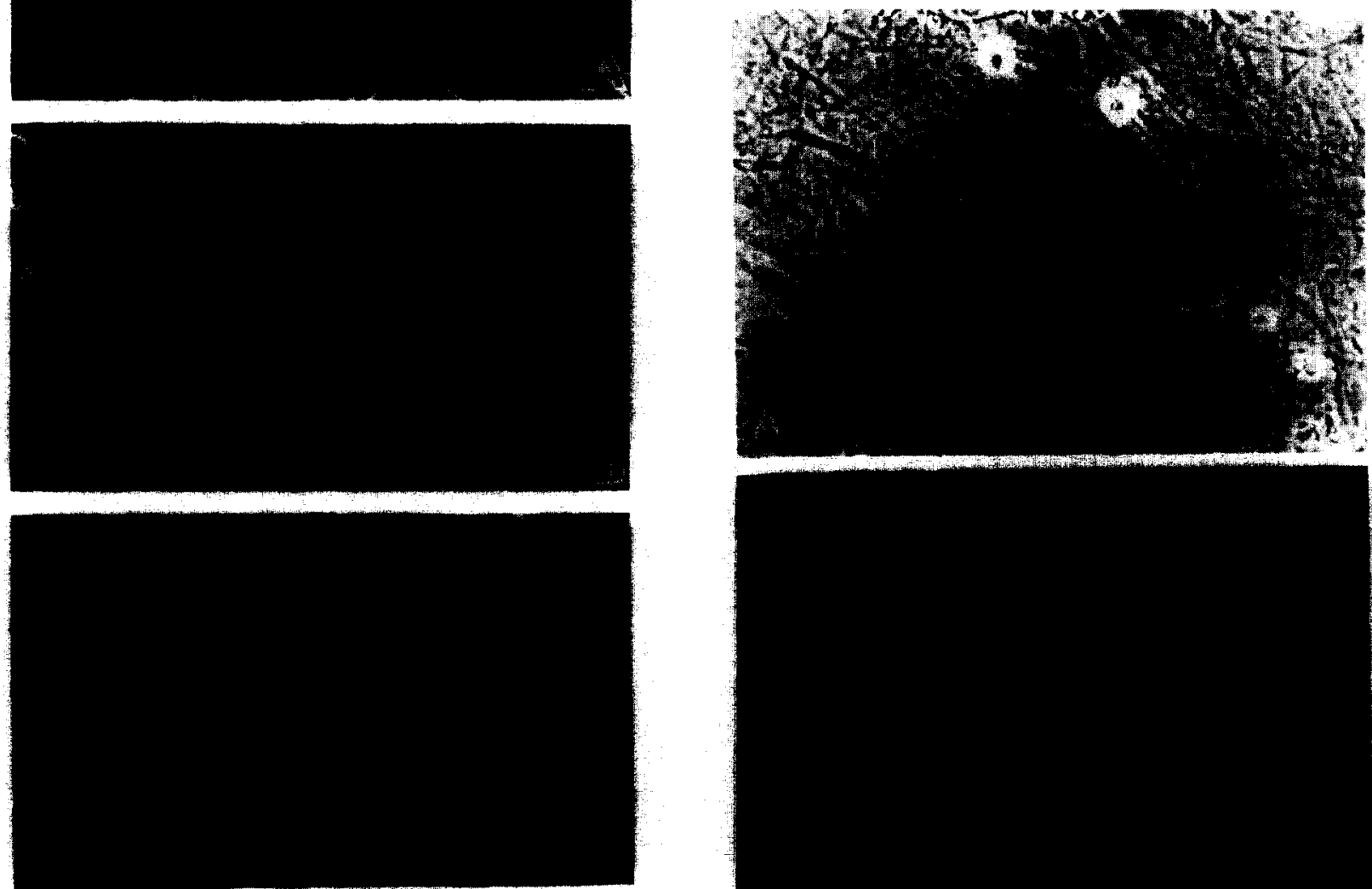

Fig. 4. Absence of fibronectin on MCAb 51-positive colonies. The double-label immunofluorescence experiment was done using rabbit antisera to fibronectin (B) followed by fluorescein labeled goat anti-rabbit serum, and then MCAb 51 which was detected by rhodamine-labeled goat anti-mouse serum (C). A. shows a phase picture of the same field shown in B and $C$. $452 \times$

the primary cerebellar cultures (Fig. 6) but these cells are not associated with the colonies. Moreover, cultures of rat brain or rat capillary enriched for endothelial cells do not bind MCAb 51 (data not shown). These findings eliminate the possibility that the antibody is recognizing endothelial cells.

\section{Binding of MCAB 51 to epithelial cells}

In light of the epithelial cell type morphology that MCAb 51-positive colonies exhibit and the absence of the antigen on a variety of neural cells, several epi-
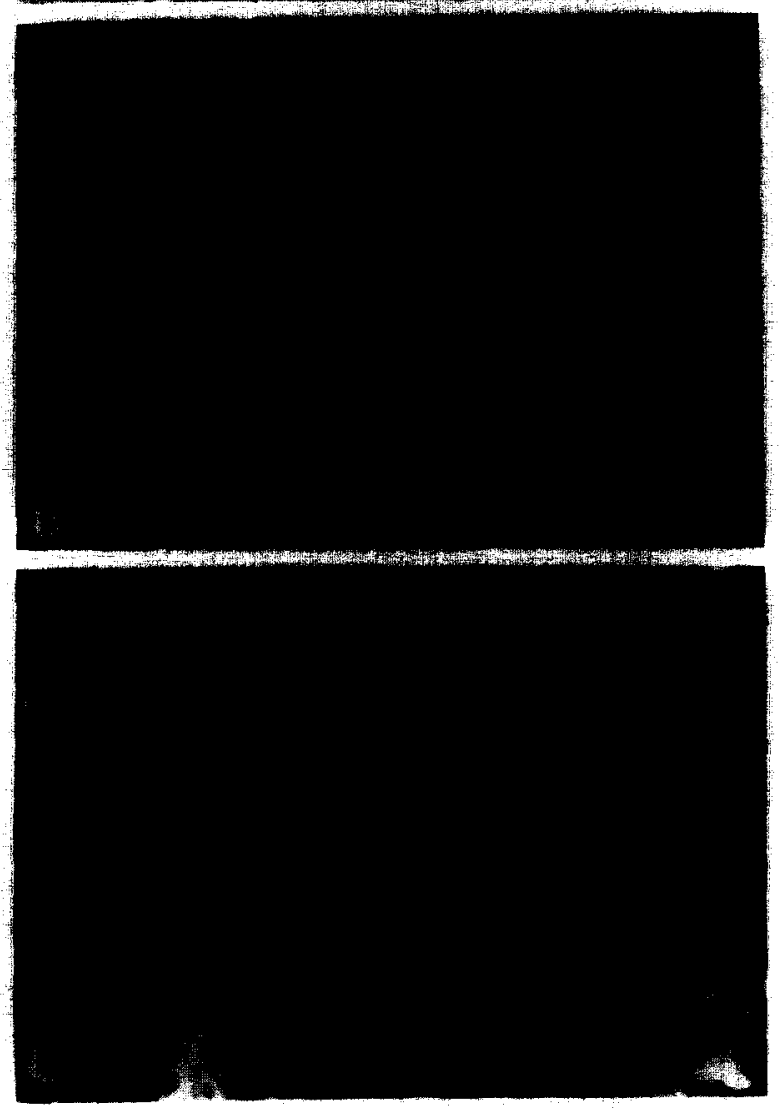

Fig. 5. Double-label immunofluorescence experiment with MCAb 51 and rabbit antisera to Thy-1. A, B and C show an identical field. $\mathrm{A}$ is a phase picture and $\mathrm{B}$ and $\mathrm{C}$ fluorescence pictures of MCAb 51 and Thy-1, respectively. Note that the colony is negative for Thy $-1.312 x$. 

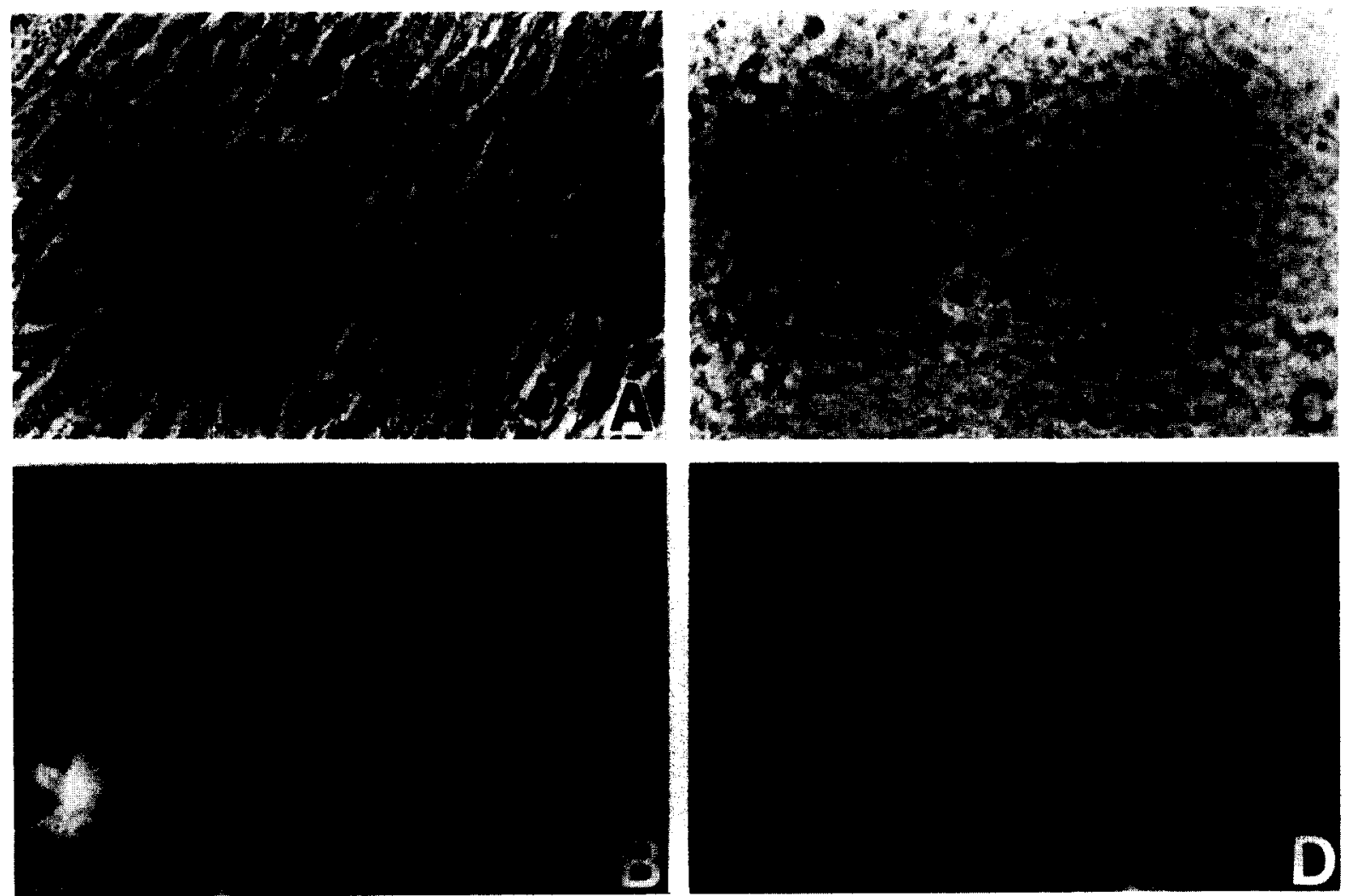

Fig. 6. Factor VIII-staining of two primary cerebellar cultures. A and C are the phase pictures of B and D respectively. Two features are worth noting. First, the cell type which reacts with Factor VIII does not appear in colonies as do those cells which react with $\mathrm{MCAb}$ 51 ; second, the cells exhibit speckled cytoplasmic fluorescence which is typical of Factor VIII staining. $776 \times$.
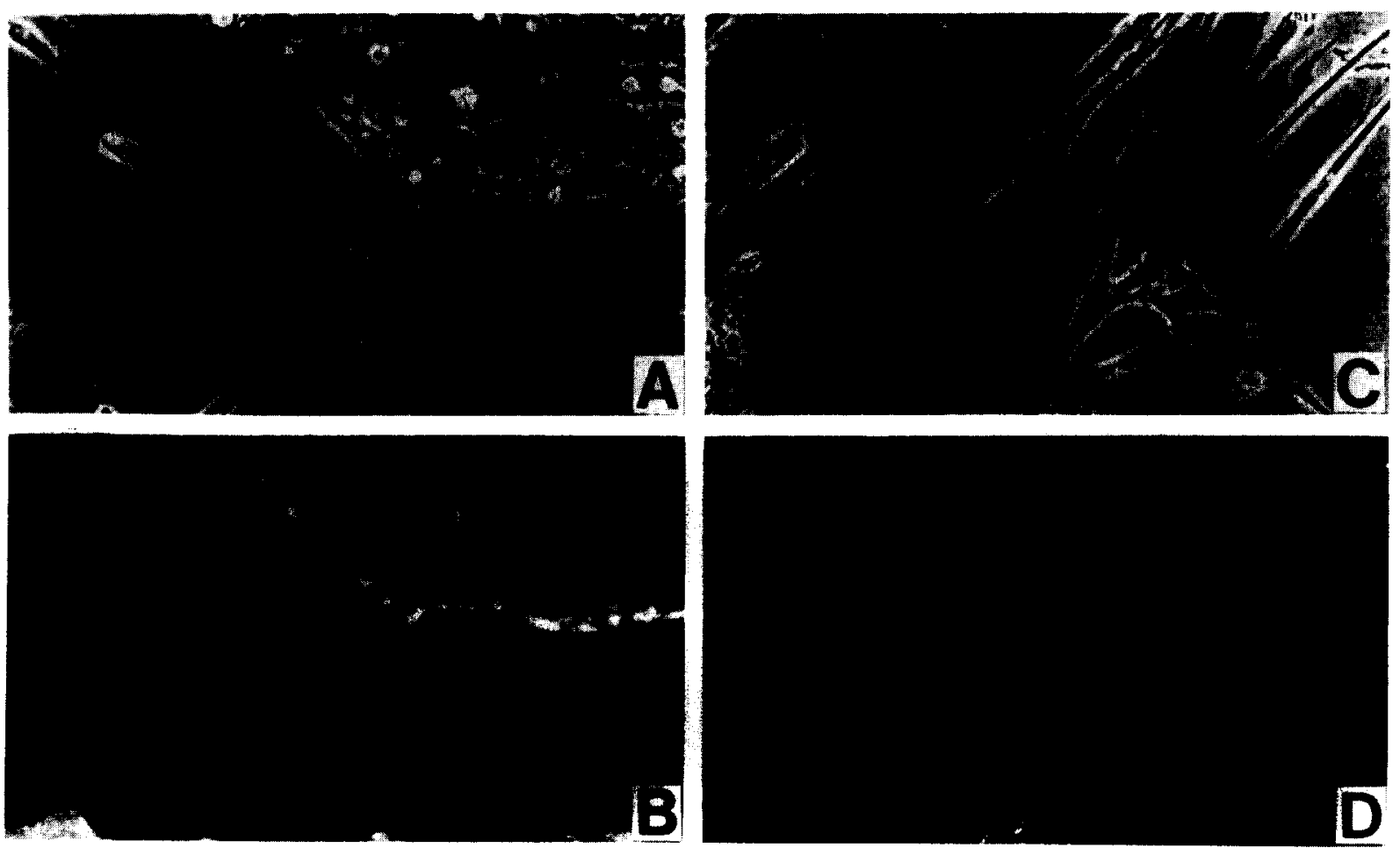

Fig. 7. MCAb 51 staining of mammary $(A, B)$ and liver $(C, D)$ epithelial primary cultures. The fluorescence associated with the mammary cultures is clustered at the edges of the colony. Liver epithelial cells do not show the fluorescence clustering phenomena. Note that a number of cells in both the mammary and liver cultures do not react with MCAb 51. Presumably some of these are fibroblasts. A and $C$ are phase and $B$ and $D$ are fluorescence pictures. $378 \times$. 

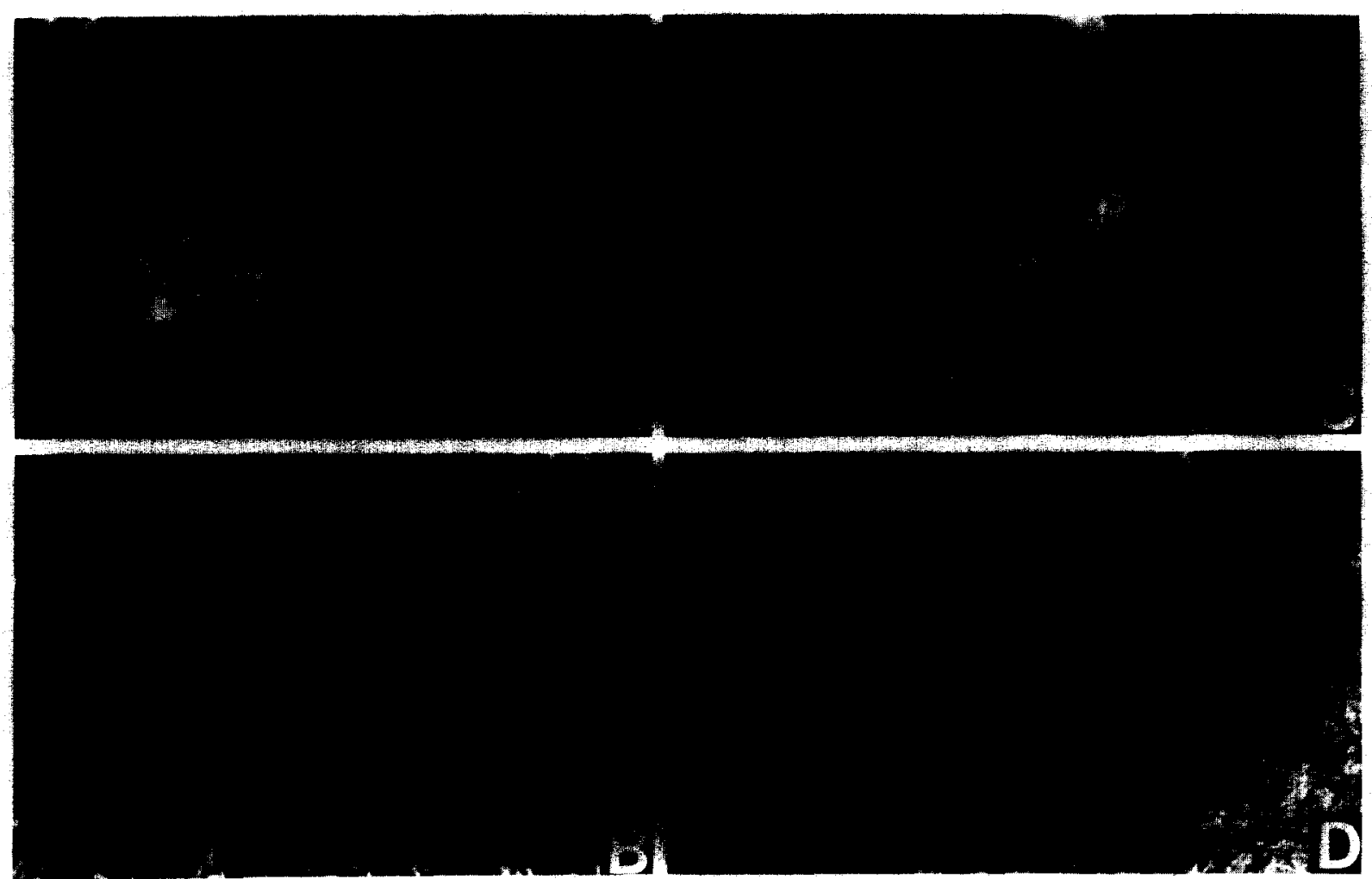

Fig. 8. Frozen sections of rat kidney (A, B) or tongue (C, D) labeled with MCAb 51. A and C are fluorescence pictures and B and D phase pictures. $669 \times$.

little or no staining is seen when other MCAbs are substituted for MCAb 51. It is worth noting that the fluorescence associated with mammary cells in culture, similar to that seen in primary cerebellar cultures, is greater for cells at the edges of the tissue than for cells in the interior. Lastly Fig. 9 shows that MCAb 51 binds to choroid plexus epithelial cells in tissue sections.

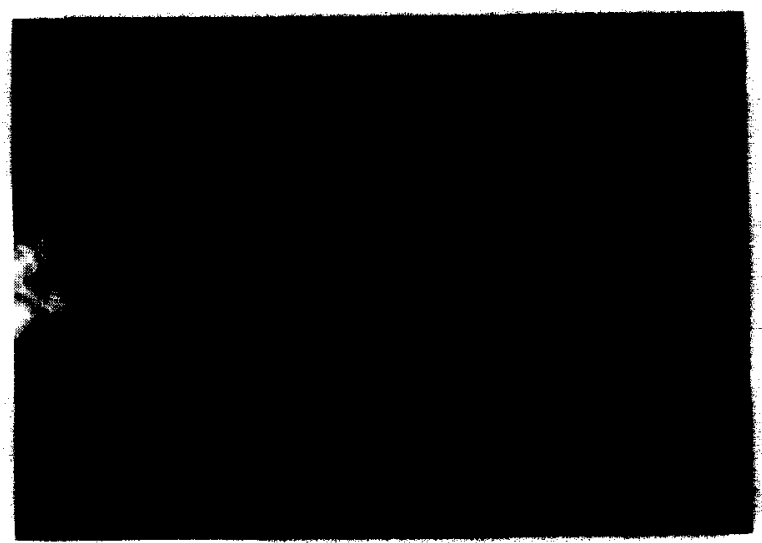

Fig. 9. MCAb 51 staining of choroid plexus in tissue section. $430 \times$.

\section{DISCUSSION}

Previous work has shown that neurons, oligodendrocytes, astrocytes and other cells associated with neural tissue can be identified utilizing cell type specific markers ${ }^{4}$. Neurons have been shown to exhibit receptors for tetanus toxin, while oligodendrocytes and astrocytes express galactoctocerebroside and GFAP, respectively. It is surprising that MCAb 51positive colonies do not exhibit any of these markers and thus do not appear to be representative of these 3 cell types. Consistent with our findings is the absence of Thy- 1 and 04 on MCAb 51-positive colonies. Thy1 is present in the nervous system on neurons, astrocytes and fibroblasts ${ }^{4,19}$. It is worth noting that GFAP $^{1,11,25}$ and Thy-18 show overlapping but non-identical staining of astrocytes. Since a priori it seems unlikely that GFAP and Thy- 1 would have the identical astrocyte subclass specificities, antiserum to Thy- 1 offers an independent means of establishing that the MCAb 51 colonies are not astrocytes.

The 04 monoclonal antibody recognizes mature and immature oligodendrocytes ${ }^{26}$. The former cell 
type is also recognized by galactocerebroside. The absence of 04 on MCAb 51-positive colonies is consistent with the colonies lacking galactocerebroside and suggests that the colonies are not immature oligodendrocytes.

Perhaps the most surprising result from the immunofluorescence experiments was the absence of fibronectin on the colonies. Fibronectin has previously been shown to be absent on neurons, oligodendrocytes and astrocytes but present on meningeal, choroid plexus, fibroblast and endothelial cells ${ }^{19,21}$. In the case of endothelial cells, however, it is unclear whether fibronectin is synthesized by the cells or is present as a result of the deposition from the blood. Although fibrorectin was absent froril numerous colonies examined, it is necessarv to note that occasionally we did observe colonies that exhibited small amounts of fibronectin. However, the number of such colonies varied considerably from one primary culture to the next, and because of this variability and the poor level of staining, we were unable to convince ourselves whether the staining is a result of synthesis and secretion of fibronectin by the cells in the colonies, or is initially produced by other cell types and subsequently adheres to the colonies.

The nature of the cell type MCAb 51 recognizes is unclear, but considering its morphology it appears to be epithelial. Indeed the fact that the antibody specifically binds to epithelial cells from neural as well as non-neural tissue supports this interpretation. The strongest piece of evidence is that MCAb 51 binds to choroid plexus cells in brain sections. The choroid plexus contains an epithelial cell layer which is derived from the ependymal lining of the ventricles ${ }^{8,17}$. Presumably the islands of flat cells that MCAb 51 binds to in primary cultures are composed of similar epithelial cells. Schachner et al.21 have shown that choroid epithelial cells exhibit fibronectin whereas our MCAb 51-positive colonies are fibronectin-negative. A word of caution should be inserted, however, when fibronectin is used as a marker for epithelial cells. Chen et al. ${ }^{3}$ have shown that not all epithelial cells express fibronectin in vitro and those that do often express levels that are low relative to the amount produced by fibroblasts. Equally important is that fibronectin expression disappears with time in vitro. Thus it is possible that MCAb 51 is recognizing epithelial cells which are fibronectin-negative in culture.
In regard to the epithelial cell-type specificity of MCAb 51 it is important to note that a key marker for epithelial cells is the cytoplasmic protein keratin. Keratin is a term which encompasses a family of related intermediate filaments, members of which are thought to be expressed in epithelial cells in different stages of differentiation ${ }^{27}$. Previous investigators have shown that keratin is absent from neural tissue ${ }^{12,27}$. Thus MCAb 51 may prove to be a valuable new marker for epithelial cells in that it recognizes a cell surface antigen with a specificity that is distinct from, yet overlaps that of keratin.

Most interesting in light of MCAb 51's unique celltype specificity in a primary culture is the finding that 11 out of 12 of the RSV lines are positive. There are several possible explanations for this observation. First, the expression of the antigen could be a consequence of transformation such that the normal cell types which were initially transformed were negative but as a consequence of transformation the cell lines express the antigen. Thus, one might expect all the RSV as well as the ENU lines to be positive. However, since one RSV line does not exhibit the antigen, and only 2 out of 9 of the ENU lines do, it is unlikely that antigen expression is a result of transformation. Indeed, the observation that the RSV lines express the antigen at the temperature at which the transforming effect of the virus is abrogated suggests that the expression of the antigen in the lines is not linked to the transforming capacity of the virus.

A second explanation that might account for the observation that all but one of the RSV-transformed lines are positive for the antigen is that RSV may be selectively transforming neuroepithelial cells which are positive for the MCAb 51 antigen in perinatal animals. This hypothesis is supported by two findings: first, in primary cultures from perinatal animals only epithelial-like cells exhibit the MCAb 51 antigen; and, second, 11 out of $12 \mathrm{RSV}$-transformed cell lines derived from perinatal animals exhibit the antigen. However, there is no evidence in the literature by others that suggests that RSV exhibits such cell typespecific transforming potential. Indeed studies have shown that RSV yields tumors which are predominantly gliomas ${ }^{9}$, whereas our previous findings indicated that both astrocytic glial and neuronal cells were transformed ${ }^{5-7}$. These data may be reconcilable if RSV transforms multipotential neuroepithelial 
precursor cells that have the capacity to exhibit a variety of properties as they differentiate ${ }^{25}$. If this is the case, however, then one needs to explain why in both primary cultures and tissue sections, glia and neurons do not show MCAb 51 staining. A possible explanation is that they carry the antigen but at levels too low to be detectable by immunofluorescence. This point may be resolved by assaying for MCAb 51binding by radioimmune assay. Alternatively, the MCAb 51 antigen may disappear as neurons and glia mature and expression is retained only on epithelial cells in the adult, for example choroid plexus epithelial cells.

It is worth noting that the work of other investigators has suggested that neuroepithelial cells can be transformed with ENU and that cell lines generated from them are multipotential ${ }^{10,29}$. Assuming that RSV is similarly transforming multipotential neuroepithelial cells it is striking that only 2 out of 9 cell lines generated with ENU bind MCAb 51 while 11 out of 12 RSV lines do. This suggests that most of the

\section{REFERENCES}

1 Bignami, A. and Dahl, D., Astrocyte-specific protein and neuroglial differentiation. An immunofluorescence study with antibodies to the glial fibrillary acidic protein, J. comp. Neurol., 153 (1974) 27-38.

2 Chen, Y. C., Hayman, M. J. and Vogt, P. K., Properties of mammalian cells transformed by temperature-sensitive mutants of avian sarcoma virus, Cell, 11 (1977) 513-521.

3 Chen, L. B., Maitland, N., Gallimore, P. H. and McDougall, J. K., Detection of the large external transformationsensitive protein on some epithelial cells, Exp. Cell Res., $106(1977) 39-46$

4 Fields, K. C., Cell type-specific antigens of cells of the central and peripheral nervous system. In A. A. Moscona, A. Monroy and R. K. Hunt (Eds.), Current Topics in Developmental Biology, Vol. 13, Academic Press, New York, 1979, pp. 237-257.

5 Giotta, G. J., Heitzmann, J. and Cohn, M., Immunological identification of cerebellar cell lines, Develop. Brain Res., 4 (1982) 209-221.

6 Giotta, G. J., Heitzmann, J. and Cohn, M., Properties of two temperature-sensitive Rous sarcoma virus-transformed cerebellar cell lines, Brain Res., 202 (1980) 445-458.

7 Heitzmann, J., Giotta, G. J. and Cohn, M., Monoclonal antibodies and the identification of cerebellar cell lines. In Monoclonal Antibodies Against Neural Antigens, Cold Spring Harbor, New York, 1981, pp. 51-60.

8 Jacobson, M., Developmental Neurobiology, Plenum, New York, 1978

9 Janisch, W. and Schreiber, D., In D. D. Bigner and J. A. Swenberg (Eds.), Experimental Tumors of the Central Ner vous System, UpJohn, Kalamazoo, 1977.
ENU transformed cell lines either do not make the antigen, or have amounts below the level of detection by immunofluorescence. Future experiments are aimed at determining if this may be accounted for by the fact that all of the RSV lines are of cerebellar origin whereas the ENU lines are of uncertain anatomical origin. An alternative explanation is that the MCAb 51 antigen may appear perinatally in development and thus be present on the RSV lines which were derived from perinatal animals, but not on the ENU lines which were established from earlier fetuses.

\section{ACKNOWLEDGEMENTS}

We would like to thank Dr. David Schubert for providing the chemically transformed brain lines. We also thank Chris Knox and Diedre O'Connor for help with some of the experiments. This work was supported by grants from the National Cancer Institute to G.J.G. (1R23 CA24393-04CBY).

10 Kimes, B., Tarikas, H. and Schubert, D., Neurotransmitter synthesis by two clonal nerve cell lines: changes with culture growth and morphological differentiation, Brain Res., 79 (1974) 291-295.

11 Lagenaur, C., Sommer, I, and Schachner. M., Subclass of astroglia in mouse cerebellum recognized by monoclonal antibody, Develop. Biol., 79 (1980) 367-378.

12 Lane, B. E., Monoclonal antibodies provide specific intramolecular markers for the study of epithelial tonofilament organization, J. Cell Biol., 92 (1982) 665-673.

13 Leffert, H. L., Koch, K. S., Moran, T. and Williams, M., Liver cells. In W. B. Jakoby and I. Pastan (Eds.), Methods of Enzymology, Vol. 58, Academic Press, New York, 1979. pp. 536-544.

14 Lesley, J, and Lennon, V., Thy-1 antigen expression on rat brain cell lines, Brain Res., 153 (1978) 109-120.

15 Mirsky, R., Wendon, L., Black, P. Stolkin, C. and Bray, D., Tetanus toxin: a cell surface marker for neurones in culture, Brain Res., 148 (1978) 251-259.

16 Jaffe, E. A., Hoyer, L. W. and Nachman, R. L., Synthesis of antihemophilic factor antigen by cultured human endothelial cells, J. clin. Invest., 52 (1973) 2757-2764.

17 Peters, A., Palay. S. L. and Webster, H. D., The Fine Structure of the Nervous System: the Neurons and Supporting cells, Saunders, Philadelphia, 1976.

18 Pruss, R. M., Thy-1 antigen on astrocytes in long term cultures of rat central nervous system, Nature (Lond.), 280 (1980) 688-690

19 Raff, M. C., Fields, K. L., Hakomori, S., Mirsky, R., Pruss, R. and Winter, J., Cell type-specific markers for distinguishing and studying neurons and the major classes of glial cells in culture, Brain Res., 174 (1979) 283-308.

20 Raff, M., Mirsky, R., Fields, K., Lisak, R., Dorfman, S. Silberberg, D., Gregson, N., Leibowitz, S. and Kennedy, 
M., Galactocerebroside is a specific cell surface antigenic marker for oligodendrocytes in culture, Nature (Lond.), 266 (1978) 364-366.

21 Schachner, M., Schoonmaker, G. and Hynes, R. O., Cellular and subcellular localization of LETS protein in the nervous system, Brain Res, 158 (1978) 149-158.

22 Schier, B. K., Wilson, S. H. and Nirenberg, M., Cultured cell systems and methods for neurobiology. In S. Fleischer and L. Parker (Eds.), Methods in Enzymology, Vol. 32, Academic Press, New York, 1974, pp. 765-783.

23 Schubert, D., Heinemann, S., Carlisle, W., Tarikas, H. Kimes, B., Patrick, J., Steinbach, J. H., Culp, W. and Brandt, B. L., Clonal cell lines from the rat central nervous system, Nature (Lond.), 249 (1974) 224-227.

24 Schulman, M., Wilde, C. D. and Köhler, G., A better cell line for making hybridomas secreting specific antibodies, Nature (Lond.), 276 (1978) 269-271.

25 Skoff, R. P., Price, D. L., and Stockes, A., Electron microscopic autoradiographic studies of gliogenesis in rat optic nerve. II. Time of origin, J. comp. Neurol., 169 (1976) 313-334.

26 Sommer, I. and Schachner, M., Monoclonal antibodies (01 to 04$)$ to oligodendrocyte cell surfaces: an immunocytological study in the central nervous system, Develop. Biol., 83 (1981) $311-322$.

27 Tseng, S. C. G., Jarvinsen, M. J., Nelson, W. G., Huand, J. W., Woodcock-Mitchell, J., and Sun, T. T., Correlation of specific keratins with different types of epithelial differentiation: Monoclonal antibody studies, Cell, 30 (1982) $361-372$.

28 Topper, Y. J., Oka, T. and Vonderhaar, B. K., Techniques for studying development of normal mammary epithelial cells in organ culture. In J. Hardman and B. O'Malley (Eds.), Methods in Enzymology, Vol. 39, Academic Press, New York, 1975, pp. 443-454.

29 West, G. J., Vki, J. Stahn, R. and Herschman, H. R., Neurochemical properties of cell lines from N-ethyl-N-nitrosourea-induced rat tumors, Brain Res., 130 (1977) 387-392. 